\title{
El sistema de la lucha contra la corrupción en Italia. Características, tendencias y problemas abiertos
}

\author{
The anti-corruption system in Italy. \\ Features, trends and opened problems
}

Enrico Carloni

Università degli studi di Perugia enrico.carloni@unipg.it

\section{RESUMEN}

El objetivo de este trabajo es ilustrar de una manera sintética, pero completa, el sistema que resulta de este marco normativo, con el objetivo de introducir el estudio de la políticas anticorrupción en Italia y de las instituciones llamadas a ponerlas en práctica.

\section{PALABRAS CLAVE}

Ley contra la corrupción, reforma administrativa, Administración Pública italiana.

\section{ABSTRACT}

The aim of this work is to illustrate in a synthetic, but overall, the system resulting from this regulatory framework with the aim of introducing the study of anti-corruption policies in Italy and the institutions called upon to realize them.

\section{KEYWORDS}

Law against corruption, administrative reform, Italian Public Administration.

\section{SUMARIO}

1. PREMISA. 2. LA CORRUPCIÓN «ADMINISTRATIVA» Y EL PERÍMETRO DE LAS NUEVAS NORMAS. 3. LA AUTORIDAD NACIONAL DE LUCHA CONTRA LA CORRUPCIÓN. 4. LOS PLANES DE PREVENCIÓN DE LA CORRUPCIÓN. 5. EL FORTALECIMIENTO DE LA IMPARCIALIDAD DE LOS FUNCIONARIOS: CONFLICTOS DE INTERESES Y NORMAS DE CONDUCTA. 6. LA TRANSPARENCIA ADMINISTRATIVA MEDIANTE LA OBLIGACIÓN DE PUBLICACIÓN. 7. EL NUEVO DERECHO GENERAL DE ACCESO. 8. LA NUEVA NORMATIVA DE CONTRATACIÓN PÚBLICA. 9. OBSERVACIONES FINALES. 


\section{PREMISA}

El modelo italiano de la prevención de la corrupción constituye en la actualidad un interesante punto de referencia en la reciente creación de sistemas administrativos para combatir la corrupción: un problema que caracteriza Italia ${ }^{1}$ de forma marcada, pero que es un problema evidente también en otros países, entre los que se hallan los del sur y el este de Europa. La estrategia italiana, que representa una novedad en un país que tradicionalmente no había desarrollado un enfoque orgánico y global dirigido a contener los fenómenos de corrupción ${ }^{2}$, se caracteriza por una serie de elementos que merecen ser ilustrados para describir el «sistema» italiano, con sus puntos fuertes y sus puntos débiles, tal y como han surgido y se han planteado en el lustro posterior a la ley núm. 190 de 2012, que marcó su fundación.

En términos normativos, su diseño se remonta a la ley «anticorrupción», núm. 190 de $2012^{3}$, también conocida como ley «Severino», por el nombre del Ministro de Justicia del Gobierno de Monti, quien la promovió también a raíz de una serie de exigencias internacionales ${ }^{4}$ : una ley que no es de fácil lectura, empezando por su estructura (la normativa está contenida esencialmente en un único artículo, el primero, de hasta 83 apartados), que establece directamente una parte de la regulación del nuevo sistema y contiene una serie de delegaciones en el gobierno en cuanto a la regulación de otras partes ${ }^{5}$. Sobre la base de estas delegaciones, el Gobierno aprobó dos decretos legislativos clave (el núm. 33 de $2013^{6}$, en materia de transparencia; y el núm. 39 de 20137, en materia de incompatibilidades y de inadecuación de nombramientos) y otras medidas, incluido, en particular, el reglamento relativo a los códigos de conducta (Decreto Presidencial núm. 62 de 2013) ${ }^{8}$. Este «paquete» es el núcleo fundamental y original del plan de lucha contra la corrupción, al que, además, se han añadido medidas posteriores que han tratado de reforzar el papel y las competencias de la autoridad de garantía y han reformado algunas instituciones.

Entre los principales cambios e innovaciones, cabe destacar como decisivos al menos otras tres medidas: la abolición de la autoridad para los contratos públicos con la transferencia de las competencias a la Autoridad Nacional Anticorrupción, reforzada al mismo tiempo en lo que respecta a su papel y funciones en materia de transparencia y de prevención de la corrupción (Decreto Legislativo núm. 90 de 2014, convertido en la Ley núm. 114 de $2014^{9}$ ); la reforma de la normativa en materia de transparencia administrativa, en el marco de las políticas generales de reforma administrativa (la denominada reforma «Madia» ${ }^{10}$ ), mediante

1 Cfr. especialmente A. VANNUCCI, "La corruzione in Italia: cause, dimensioni, effetti", in La legge anticorruzione, ed. B. G. MATTARELLA, M. PELISSERO, Turín, Giappichelli, 2013, págs. 25 y ss.; Comisión Europea. Encuesta Eurobarómetro 76.1, Corrupción, febrero de 2012, TNS, Opinion \& Social, 2012, especial 374, en http://ec.europa.eu/commfrontoffice/publicopinion/archives/ebs/ ebs_374_en.pdf; Quality of Government Institute, Measuring the Quality of Government and Sub-national variations a dataset, 2010, en http://www.qog.pol.gu.se/data/euproject.

2 Cfr. D. DELLA PORTA, A. VANNUCCI, "The controversial legacy of 'mani pulite': a critical analisys of italian corruption and anti-corruption policies", en Bullettin of Italian Politics, 2009, págs. 233 y ss.; GRECO - Group of States Against Corruption, Evaluation report on Italy, Estrasburgo, Consejo de Europa, 2008. Commissione per lo studio di misure per la trasparenza e la prevenzione della corruzione, La prevenzione della corruzione: per una politica di prevenzione, 2011, en http://www.governo.it/Governolnforma/documenti/20121022/rapporto corruzioneDEF.pdf.

3 Ley núm. 190 , de 6 noviembre de 2012, de medidas para la prevención y la lucha contra la corrupción y la ilegalidad en la administración pública (Gazzetta ufficiale (G. U., Diario Oficial italiano) núm. 265 de 13 de noviembre de 2012).

${ }^{4}$ Acerca del «contexto externo» que justifica y exige esta acción, cfr. S. BONFIGLI, "L'Italia e le politiche internazionali di lotta alla corruzione", en F. MERLONI, L. VANDELLI, L. (eds.), La corruzione amministrativa. Cause, prevenzione e rimedi, Bolonia, II Mulino, 2010, 109 y ss.

${ }_{5}$ Sobre la ley núm. 190 de 2012, La legge anticorruzione, ed. cfr. B. G. MATTARELLA, M. PELISSERO, cit.

6 Decreto Legislativo núm. 33, de 14 de marzo de 2013, de reorganización de las disposiciones aplicables a la obligación de publicidad, transparencia y difusión de la información por parte de las administraciones públicas (G. U. núm. 80 de 5 de abril de 2013).

7 Decreto Legislativo núm. 39, de 8 abril de 2013, por el que se dictan disposiciones en materia de inadecuación de los nombramientos y de las incompatibilidades de los cargos en las administraciones públicas y en el seno de entidades privadas con participación pública, de conformidad con el artículo 1, apartados 49 y 50 de la Ley núm. 190 de 6 de noviembre de 2012 (G. U. núm. 92 de 19 de abril de 2013).

8 Decreto Presidencial núm. 62, de 16 de de abril de 2013, por el que se aprueba el reglamento del código de conducta los empleados públicos, de conformidad con el artículo 54 del Decreto Legislativo núm. 165 de 30 de marzo de 2001 (G. U. núm. 129 del martes, 04 de junio de 2013).

9 Ley núm. 114, de 11 de agosto de 2014, de conversión en Ley, con modificaciones, del Decreto Ley núm. 90 de 24 de junio de 2014 de medidas urgentes para la simplificación y la transparencia administrativa y para la eficiencia de los tribunales (G. U. núm. 190 de 18 de agosto de 2014.).

10 En términos generales, véase al respecto B. G. MATTARELLA, "II contesto e gli obiettivi della riforma, Commento a I. 7 agosto 2015”, núm. 124, en Gior. dir. amm., 2015, vol. 5, págs. 621 y ss. 
la Ley núm. 124 de $2015^{11}$ y sobre todo con el posterior Decreto Legislativo delegado núm. 97 de $2016^{12}$; el nuevo Código de la Contratación Pública, aprobado mediante el Decreto Legislativo núm. 50 de $2016^{13}$ y recientemente revisado y corregido por el Decreto Legislativo núm. 56 de $2017^{14}$.

Como puede fácilmente observarse, se trata de un marco amplio y articulado, flanqueado, además, por numerosas otras medidas de alcance más limitado y sectorial (entre ellas se encuentran las que, a partir de las regulaciones especiales para la Expo 2015 incluidas en el mismo Decreto Legislativo núm. 90 de 2014 ${ }^{15}$, y retomadas después para el Jubileo Extraordinario de la Misericordia ${ }^{16}$ y luego para la reconstrucción posterior al terremoto ${ }^{17}$, reforzaron los poderes autónomos del Presidente de la Autoridad y establecieron unos mecanismos de control específicos y la garantía de transparencia, a menudo definidos específicamente como «supervisión colaborativa»), pero sobre todo, se caracteriza por estar en movimiento y aún no totalmente estabilizado.

El objetivo de este trabajo es ilustrar de forma sintética, pero exhaustiva, el sistema que deriva de este marco normativo, con el objetivo de introducir al estudio de las políticas de lucha contra la corrupción en Italia y de las instituciones competentes para su aplicación.

\section{LA CORRUPCIÓN «ADMINISTRATIVA» Y EL PERÍMETRO DE LAS NUEVAS NORMAS}

En términos generales, la Ley 190 de 2012 es importante sobre todo porque proporciona una nueva concepción de la corrupción, que algunos comentaristas han descrito como «corrupción administrativa», que se enmarca sustancialmente en el concepto de «mala administración»: constituyen «corrupción», en esencia, «circunstancias pertinentes más amplias que las contempladas en el tipo penal», que comprenden «no solo toda la gama de delitos contra la administración pública regulados en el Título II, Capítulo I del Código Penal, sino también las situaciones en las que -independientemente de su relevancia penal- se manifieste un mal funcionamiento de la Administración debido a la utilización de las funciones asignadas para satisfacer intereses particulares» ${ }^{18}$.

Es un enfoque que integra la concepción de los especialistas, que han definido la corrupción como dinámica que «contamina» la relación entre «principal» y «agente»: se incluyen, en particular, las conductas que infringen no solo las normas del Código Penal en materia de delitos contra la Administración (la malversación, la corrupción «propia» e «impropia», el soborno, la prevaricación, el «tráfico de influencias»), sino también las que se oponen a los deberes disciplinarios o a las reglas en materia de correcta gestión de los recursos públicos, con especial atención a evitar cualquier conflicto de intereses.

11 Ley núm. 124, de 7 de agosto de 2015, por la que se disponen las delegaciones al Gobierno en materia de reorganización de la administración pública (G. U. núm. 187 de 13 de agosto de 2015).

12 Decreto Legislativo núm. 97, de 25 de mayo de 2016, de revisión y simplificación de las disposiciones sobre la prevención de la corrupción, la publicidad y la transparencia, que enmienda la Ley núm. 190 de 6 de noviembre de 2012 y del Decreto Legislativo núm. 33, de 14 marzo de 2013, en virtud de la Ley núm. 124, de 7 de agosto de 2015, sobre la reorganización de la administración pública, (G. U. núm. 132 del miércoles, 08 de junio de 2016).

13 Decreto Legislativo núm. 50, de 18 de abril de 2016, de aplicación de las Directivas 2014/23/UE, 2014/24/UE y 2014/25/UE en materia de adjudicación de contratos de concesión, de contratación pública y de los procedimientos de adjudicación de las entidades suministradoras en los sectores del agua, la energía, los transportes y los servicios postales, así como para reorganizar las normas vigentes en materia de contratos públicos de obras, servicios y suministros (G. U. núm. 91 de 19 de abril de 2016) ahora redefinido más sucintamente como "Código de contratación pública" mediante el Decreto Legislativo núm. 56 de 2017.

14 Decreto Legislativo núm. 56, de 19 de abril de 2017, por el que se aprueban disposiciones complementarias y enmiendas al Decreto Legislativo núm. 50, de 18 de abril de 2016 (G. U. núm. 103 de 5 de mayo de 2017).

15 Véase el artículo 30 del Decreto Legislativo núm. 90 de 2014, convertido en Ley núm. 114 de 2014, que atribuye al Presidente de la Autoridad Nacional de Lucha Contra la Corrupción (ANAC, por sus siglas en italiano) la facultad de establecer una Unidad Operativa Especial EXPO 2015, con funciones de apoyo para el ejercicio de las actividades de alta supervisión y garantía de la equidad y la transparencia de los procedimientos relacionados con la licitación de las obras del gran acontecimiento de la EXPO Milán 2015.

16 Véase el Acuerdo del Consejo de Ministros del 27 de agosto de 2015, que prevé (art. 1, apartado d), que «a los actos de los procedimientos contractuales aprobados [previstos en el Plan para el Jubileo] se aplica, en la medida en que sea compatible, el artículo 30, apartado 2, del Decreto Ley núm. 90 de 24 de junio de 2014».

17 De conformidad con el art. 32 del Decreto Legislativo núm. 189, de 17 de octubre de 2016, ("Medidas urgentes en favor de las poblaciones afectadas por el terremoto del 24 de agosto de 2016, convertido con enmiendas en Ley núm. 229 , de 15 diciembre de 2016 , en G. U. núm. 294 de 17 de diciembre de 2016), titulado "Supervisión de la ANAC de las actuaciones del Comisario Extraordinario", la cobertura de la alta supervisión para la EXPO 2015 (Unidad Operativa Especial), en virtud del art. 30 del Decreto Legislativo 90/2014, se ha extendido a las intervenciones de reconstrucción pública.

18 Así lo establece la Circular núm. 1 de 2013 del Ministerio de Simplificación y Administraciones Públicas, "Ley núm. 190 de 2012, Medidas de prevención y lucha contra la corrupción y la ilegalidad en la administración pública”, registrada en el Tribunal de Cuentas el 22 de marzo de 2013 (núm. reg. 3, folio núm. 54). 
No falta tampoco la atención a la vertiente más tradicional, de la persecución penal y, por consiguiente, de la regulación de los tipos penales específicos del empleado público, a los que la ley núm. 190 dedica amplia atención: el carácter innovador de la legislación reciente, sin embargo, está vinculado precisamente a la asunción de esta lógica y a este enfoque de una nueva política para combatir la corrupción a través de la «prevención» administrativa ${ }^{19}$.

Es posible aclarar ya algunos elementos característicos, en relación con el «perímetro» de aplicación de estas normas, tanto desde un punto de vista subjetivo (a qué «funcionarios» se dirigen estas medidas), como objetivo (cuáles son las entidades públicas destinatarias de las normas anticorrupción).

Es un perímetro que presenta ambigüedades.

Por un lado, está claro que la decisión de limitar el impacto de estas reglas esencialmente al personal burocrático y a las estructuras administrativas y no a las políticas. El dato es evidente en primer lugar con referencia a los órganos constitucionales (Gobierno y Parlamento) que se encuentran fuera del alcance del decreto en términos generales, y por consiguiente a su personal político (parlamentarios, ministros, cargos políticos de ámbito nacional), pero también con referencia al personal político de las regiones y, en menor medida, de las entidades locales. En resumen, se puede decir que el criterio para la aplicación de la ley depende de la combinación de las coordinadas personal político frente a personal burocrático (donde su aplicación recae principalmente bajo la responsabilidad del personal burocrático profesional), y dimensión nacional frente a dimensión territorial (donde su aplicación es inversamente proporcional a la dimensión territorial, y por lo tanto es responsabilidad en mayor medida de las entidades locales frente a las nacionales).

Por otro lado, es especialmente extensa la concepción de «administración pública» a la que se aplica la nueva normativa, bajo la que se engloba no solo las articulaciones del Estado, las administraciones regionales y locales ${ }^{20}$ y demás entidades públicas, sino también los sujetos formalmente privados pero que están «controlados» por la Administración Pública. Todo ello, además, dentro de un plan más amplio de reorganización de las empresas públicas que tiene como objetivo distinguir más claramente entre las empresas públicas que operan en el mercado y las empresas controladas por organismos públicos y que son financiadas por estas entidades o que son destinatarias directas de contratos o de licitaciones de servicios («in house»). Para esta segunda tipología, que constituyen, así visto, organizaciones creadas para atender los intereses públicos o que hacen uso de los recursos públicos, existe el problema de cómo asegurar que se garantizan adecuadamente su transparencia e imparcialidad, aunque con algunas características específicas en comparación con las administraciones públicas tradicionales.

\section{LA AUTORIDAD NACIONAL DE LUCHA CONTRA LA CORRUPCIÓN}

El eje alrededor del cual gira el nuevo sistema es una autoridad independiente específica, la Autoridad Nacional de Lucha Contra la Corrupción (ANAC), que se ha convertido en la principal protagonista en un corto período de tiempo, y por ello a veces criticado, en la evolución del sistema administrativo italiano.

En la experiencia italiana, la introducción de un organismo responsable de la coordinación de las políticas, la definición de la acción directora y con funciones de vigilancia y control en materia de corrupción tiene una historia turbulenta, que se puede recordar muy brevemente.

Después de unos años en los que, en ausencia también de una política integral en la materia, las funciones podían considerarse competencia del Ministerio de Administraciones Públicas ( $\mathrm{y}$, en particular, en su seno, del Servicio de Lucha Contra la Corrupción y de la Transparencia, SAET, por sus siglas en italiano) ${ }^{21}$,

19 Cfr. esp. M. PELISSERO, "La nuova disciplina della corruzione tra prevenzione e repressione" y M. CLARICH, B. G. MATTARELLA, "La prevenzione della corruzione", en B. G. MATTARELLA, M. PELISSERO (eds.), La legge anticorruzione cit., págs. 374 y ss.; págs. 59 y ss.

20 El sistema de lucha contra la corrupción tiene una capacidad especial, y muy importante, de afectar a la autonomía organizativa de las regiones y las entidades locales, y por lo tanto ayuda a re-construir un sistema administrativo con mayor uniformidad: sobre este punto, cfr. ampliamente F. Merloni, "L'applicazione della legislazione anticorruzione nelle Regioni e negli enti locali tra discipline unitarie e autonomia organizzativa", en Istituzioni del federalismo, 2013, 349 y ss.

21 La Ley núm. 133, de 6 de agosto de 2008, de "Conversión del Decreto Ley núm. 112 del 25 de junio de 2008 por el que se aprueban las medidas urgentes para el desarrollo económico, la simplificación, la competitividad, la estabilización de las finanzas públicas y la nivelación tributaria (G. U. núm. 195 del 21 de agosto de 2008), en su art. 68, con la supresión de la figura del Alto Comisionado para la Anticorrupción, transfirió sus competencias al Departamento para la Función Pública, en el que se estableció el servicio correspondiente (el SAET, precisamente). 
tras la fugaz, pero sobre todo «débil» experiencia del Alto Comisionado para la Anticorrupción ${ }^{22}$, un paso importante fue la creación de un organismo especial (la Comisión para la Evaluación, la Integridad y la Transparencia, CIVIT, por sus siglas en italiano), que se instituyó para garantizar la eficiencia y la productividad del personal y de los organismos públicos y su transparencia, en el marco de las reformas de 2009 (Decreto Legislativo núm. 150/200923, conocido como «decreto Brunetta») ${ }^{24}$.

En torno a este organismo se desarrolla la nueva autoridad de garantía: en primer lugar, la CIVIT se sitúa como punto de referencia nacional de las políticas anticorrupción en 2012, y poco después, con el Decreto Ley núm. 101 de 2013, se transforma en la Autoridad Nacional de Lucha Contra la Corrupción ${ }^{25}$. Desde entonces se ha producido un progresivo fortalecimiento de esta Autoridad, de la que se ha reforzado en primer lugar la independencia y, a continuación, los poderes, sobre todo con dos medidas ulteriores que primero hicieron confluir en la ANAC las facultades, las funciones y el personal de la ya suprimida Autoridad de Supervisión de la Contratación Pública ${ }^{26}$ y, después, concentraron más claramente en el ANAC todas las funciones en materia de transparencia y anticorrupción (trasladando al mismo tiempo al Ministerio de Administraciones Públicas las competencias en materia de eficiencia y rendimiento del personal que pertenecían a la CIVIT $)^{27}$.

El resultado es una situación en la que la ANAC es responsable, como autoridad, de tres macroáreas: la lucha contra la corrupción, la transparencia (entendida, como veremos, esencialmente como la obligación de publicación) y la contratación pública; se trata, sin embargo, de áreas que interactúan entre sí, y de hecho, la autoridad no solo ve reforzada su capacidad de comprensión de los fenómenos, sino también la de intervención, y su propia capacidad de influir en las acciones de las administraciones, por esta ampliación de áreas de intervención ${ }^{28}$.

En particular, se establece un núcleo central de funciones en la misma ley núm. 190, art. 1, párrafo 2: la ANAC colabora con los organismos extranjeros homólogos, con las organizaciones regionales e internacionales competentes; adopta el Plan Nacional de Lucha Contra la Corrupción; analiza las causas y los factores de la corrupción e identifica las acciones que pueden favorecer la prevención y el combate; ejercer la supervisión y el control de la aplicación real y la eficacia de las medidas adoptadas y del respeto de las normas sobre la transparencia de la actividad administrativa; ejercer la supervisión y el control de los contratos públicos de obras, servicios y suministros; informar al Parlamento sobre las actividades de lucha contra la corrupción y la ilegalidad en la administración pública y sobre la eficiencia de las medidas en vigor.

Las funciones son ejercidas por un órgano colegiado, el Consejo de la ANAC, compuesto por cinco miembros designados por el Gobierno, previo dictamen favorable (con mayorías de garantía) de las comisiones parlamentarias pertinentes, entre los que se encuentra un Presidente.

A las facultades que se ejercen colegialmente hay que sumarles las competencias especiales que la ley ha confiado al Presidente, que es responsable de un tipo de función institucional de garantía de la legalidad y la equidad que se «activa» en situaciones excepcionales: para los hechos relacionados con los escándalos

22 La ley núm. 3, de 16 de enero de 2003, por el que se aprueban medidas de ordenación en materia de Administraciones Públicas (G. U. núm. 15 del 20 de enero de 2003), en el art. 1 prevé el nombramiento del Alto Comisionado para la prevención y el combate de la corrupción y demás formas de actos ilícitos en el seno de la administración pública, situándolo «en dependencia funcional directa del Presidente del Consejo de Ministros».

23 Decreto Legislativo núm. 150, de 27 de octubre de 2009, de aplicación de la Ley núm. 15, de 4 de marzo de 2009 , en materia de optimización de la productividad del trabajo público y de la eficiencia y la transparencia de laa administraciones públicas, (G. U. núm. 254 del 31 de octubre de 2009).

24 En aplicación del artículo 4, apartado 2, letra f) de la Ley núm. 15, de 4 de marzo de 2009, el Decreto núm. 150 del mismo año creó, en virtud de su art. 13, la Comisión para la Evaluación, la Transparencia y la Integridad de las Administraciones Públicas, «que opera en posición de independencia de juicio y de evaluación y con autonomía plena».

25 Con la entrada en vigor de la Ley núm. 125 de 2013 de conversión del Decreto Ley núm. 101, de 31 de agosto de 2013 , la CIVIT, ya identificada como «Autoridad Nacional de Lucha Contra la Corrupción» por la Ley núm. 190 de 2012, adoptó la denominación de Autoridad Nacional de Lucha Contra la Corrupción y para la Evaluación y la Transparencia de las Administraciones Públicas (ANAC). El nombre actual de «Autoridad Nacional de Lucha Contra la Corrupción» es el resultado de una modificación adicional aportada por el Decreto Ley núm. 90 de 2014

26 Véase, en particular M. CORRADINO, I. LINCESSO, "La soppressione dell'Avcp e il trasferimento delle funzoni all'Anac", en R. CANTONE, F. MERLONI (eds.), La nuova autorità nazionale anticorruzione, cit., págs. 11 y ss.

27 Cfr. M. DE ROSA, F. MERLONI, I/ trasferimento delle funzioni in materia di prevenzione della corruzione, ivi, págs. 51 y ss.; E. D'ALTERIO, “I nuovi poteri dell'Autorità nazionale anticorruzione: 'post fata resurgam'”, en Giornale di diritto amministrativo, 2015, págs. 757 y ss.

28 Véase ampliamente en R. CANTONE, F. MERLONI (eds.), La nuova Autorità anticorruzione, Turín, Giappichelli, 2015. La importancia de esta integración es destacada por la misma Autoridad: véase Autorità nazionale anticorruzione, Relazione Annuale al Parlamento dell'Autorità Nazionale Anticorruzione per l'anno 2015, Roma, 2016. 
y los procedimientos para la realización de la EXPO de Milán, o en términos generales con respecto a las empresas adjudicatarias de los contratos involucrados en delitos de corrupción y mafia.

Esta tendencia del sistema italiano de recurrir a la figura del Presidente de la ANAC en situaciones de emergencia y de crisis (EXPO, el terremoto, el Jubileo), reforzando su función y competencias ${ }^{29}$, ha contribuido a que el actual titular del cargo, Raffaele Cantone (ya conocido como un importante juez antimafia), se convierta en una figura central en el debate público y político nacional.

Esta visibilidad del Presidente, y por lo tanto de la ANAC en su conjunto, tiene aspectos positivos y negativos: se alimenta la atención del público sobre las cuestiones de la lucha contra la corrupción y sobre la legalidad, pero por otra parte se pueden sobrecargar las expectativas sobre la capacidad "todopoderosa» de las estructuras de la lucha contra la corrupción para resolver un problema complejo y arraigado, como es la corrupción (entendida tanto en su sentido más estricto como en el más amplio de «mala administración») en el sistema administrativo italiano.

Este último aspecto puede ser problemático: la ley de lucha contra la corrupción, y las medidas posteriores, no dotan a la Autoridad de poderes similares a los de la autoridad judicial (de investigación, y mucho menos de condena), sino esencialmente de poderes destinados a garantizar la aplicación efectiva de las medidas de prevención de la corrupción por parte de las administraciones, y esto principalmente a través de poderes de orden y de poderes sancionatorios (limitados). La ANAC tiene mayor poder en materia de contratación pública, pero en general se considera que realiza sobre todo una función de dirección (especialmente a través de sus propias directrices) y de vigilancia del cumplimiento de las obligaciones de transparencia y prevención de la corrupción. A pesar de estas limitaciones, no faltan críticos que se quejan, por el contrario, de los «excesivos» poderes de la Autoridad.

\section{LOS PLANES DE PREVENCIÓN DE LA CORRUPCIÓN}

El mecanismo principal en torno al cual se desarrolla el sistema de prevención de la corrupción es el de los «planes de lucha contra la corrupción»: se trata de un plan nacional, aprobado por la Autoridad Nacional de Lucha Contra la Corrupción, con una duración de tres años y sometido a actualizaciones anuales, a través del cual la ANAC ofrece a cada una de las administraciones públicas las indicaciones, tanto metodológicas como de contenidos, para la adopción de sus propios planos (trienales) de prevención de la corrupción $(P T P C)^{30}$. El plan nacional contiene, en resumen, los objetivos estratégicos para el desarrollo de la estrategia de prevención a nivel central y proporciona orientación y apoyo a las administraciones públicas para la ejecución de la prevención de la corrupción y la redacción de sus Planes Trienales.

En cada administración pública, por lo tanto, nos encontramos con un plan específico de tres años, también sometido a una actualización anual, que, partiendo de un análisis del contexto, de los casos de corrupción y de mala gestión, de los procedimientos y de sus correspondientes «niveles de riesgo», programa las acciones necesarias para contener y prevenir el riesgo.

Según lo indicado por la ley «anticorrupción», las administraciones públicas definen «un plan de prevención de la corrupción que proporciona una evaluación de los diferentes niveles de exposición al riesgo de corrupción de los distintos departamentos y muestra las medidas organizativas dirigidas a prevenir dicho riesgo» (art. 1, apartado 5, letra a) de la Ley 190/2012).

Por tanto, se sigue el modelo conocido como «risk assessment», la evaluación del riesgo: dado un alto riesgo de corrupción, se necesitarán medidas sólidas de organización, transparencia, control, regulación preventiva de los procedimientos, etcétera. Medidas que se convertirán en menos necesarias si el riesgo resultase ser reducido: es una operación que comienza a partir de una nada sencilla acción de evaluación del riesgo de corrupción, que hay que realizar tanto en términos generales con respecto a toda la administración como, y especialmente, con respecto a los sectores individuales de intervención y a los procedimientos individuales ${ }^{31}$.

29 En relación con los poderes específicos del Presidente de la Autoridad véase R. CANTONE, B. CUCCAGNA (eds.), "I poteri del Presidente dell'Anac nel d.I. n. 90", en R. CANTONE, F. MERLONI (eds.), La nuova autorità nazionale anticorruzione, cit., págs. 97 y ss.

30 F. MERLONI, "I piani anticorruzione e i codici di comportamento", en Diritto penale e processo, 2013, núm. 8S, págs. 4 y ss.; F. DI CRISTINA, "I piani per la prevenzione della corruzione", en La legge anticorruzione cit., págs. 91 y ss.; F. MERLONI, "Le misure amministrative di contrasto alla corruzione", en Ragiusan, 2015, núm. 369-370, págs. 9 y ss. 2015, cit.

31 Cfr. en este sentido especialmente ANAC, Relazione Annuale al Parlamento dell'Autorità Nazionale Anticorruzione per l'anno 
El Plan Nacional, sobre la base de la información ya contenida en la citada Ley núm. 190 de 2012, identifica una serie de «áreas de alto riesgo», con respecto a cualquier administración pública: el área de contratación y promoción del personal, el ámbito de los contratos públicos, el área de las ayudas y subvenciones, el área de las medidas que producen indirectamente una ventaja económica (por ejemplo, autorizaciones o concesiones o permisos de obras y edificación); cada administración, sobre la base de sus procesos internos de evaluación de riesgos, puede identificar otras áreas.

El primer plan nacional, en 2013, proporcionó las orientaciones metodológicas para la elaboración de los planes y la «evaluación del riesgo», y todavía constituye la estructura básica sobre la cual desarrollar las actualizaciones posteriores, por consiguiente ahora el mismo nuevo plan nacional de 2016, que sustituye solo parcialmente el anterior ${ }^{32}$.

La «apuesta», que el legislador hace propia, es transferir a las administraciones públicas un modelo de prevención de riesgos que dispone de referencias a nivel nacional e internacional (con el Decreto Legislativo núm. 231 de $2001^{33}$ ) creado para la prevención de la corrupción y la responsabilidad social corporativa.

Si bien el plan nacional es preparado por la Autoridad Nacional ${ }^{34}$, a través de un proceso abierto a la participación de las partes interesadas, el plan trienal de administración, de nuevo después de un proceso participativo, es aprobado por los órganos políticos superiores, pero es redactado sustancialmente por el responsable de la prevención de la corrupción, que es un funcionario (por lo general un alto cargo y, en el gobierno local, por el secretario municipal ${ }^{35}$ ) encargado de esta función. El hecho de que las medidas de lucha contra la corrupción se dirigen principalmente a la estructura administrativa y que corresponde a los funcionarios la redacción del plan (y luego supervisar su cumplimiento) significa que, como a menudo lamenta la misma autoridad anticorrupción, los órganos políticos a menudo viven con desinterés la fase de la redacción de las medidas y luego con fastidio la fase de su aplicación.

De acuerdo con lo dispuesto en el párrafo 9 del artículo 1 de la Ley 190, el plan de prevención de las Administraciones individuales responde así a múltiples necesidades: identificar las actividades, incluso adicionales respecto de las establecidas en el Plan Nacional de Lucha Contra la Corrupción, en cuyo ámbito "existe un mayor riesgo de corrupción, recogiendo también las propuestas de los altos cargos directivos»; establecer, para aquellas actividades de alto riesgo, mecanismos de formación, ejecución y control de las decisiones capaces de prevenir el riesgo de corrupción; establecer, especialmente con respecto a estas mismas actividades, las obligaciones de información en relación con el responsable de la prevención de la corrupción; definir los dispositivos de seguimiento del cumplimiento de las condiciones previstas por la ley o los reglamentos para la conclusión de los procedimientos; definir las formas de supervisión de las relaciones entre la administración y los sujetos co los que se estipulan contratos o que están afectados por los procedimientos de autorización, concesión o desembolso de ayudas económicas de cualquier tipo, en particular comprobando cualquier conflicto de intereses; identificar las obligaciones de transparencia «adicionales» respecto de las previstas en la ley.

Para lograr estos objetivos, el plan de prevención de cada administración se compone de otros documentos que se integran en la lógica de la prevención de la corrupción: el plan de transparencia (que contiene las

32 El 11 de septiembre de 2013, la Autoridad Nacional de Lucha Contra la Corrupción aprobó mediante resolución CIVIT núm. 72/2013, a propuesta del Departamento de la Función Pública, el Plan Nacional de Lucha Contra la Corrupción. Tras los cambios realizados con el Decreto Legislativo 90/2014, convertido, con modificaciones, en la Ley 114/2014, la Autoridad Nacional de Lucha Contra la Corrupción, el 28 de octubre de 2015, aprobó la actualización del PNLCC con la Resolución núm. 12 de 28/10/2015. El 3 de agosto de 2016, la Autoridad Nacional de Lucha Contra la Corrupción, en cumplimiento del art. 1, apartado 2-bis de la Ley 190/2012, introducido por el Decreto Legislativo núm. 97/2016, aprobó el Plan Nacional de Lucha Contra la Corrupción de 2016 con la Resolución núm. 831 del 08/03/2016.

${ }_{33}$ La introducción de medidas organizativas para la prevención de la corrupción estaba prevista, para los sujetos de naturaleza privada, mediante el Decreto Legislativo núm. 231, de 8 junio de 2001, de responsabilidad administrativa ante los delitos (G. U. del 19 de junio de 2001). En concreto, el decreto establece que (art. 6, apartado 1) si el delito fue cometido por las personas indicadas en el artículo 5, apartado 1, letra a), «el organismo no se hace responsable si prueba que [...] el órgano de dirección ha adoptado y aplicado eficazmente, antes de que el delito se hubiese cometido, los modelos de organización y gestión aptos para prevenir los delitos tipificados como el que se ha producido fehacientemente».

34 El primer Plan Nacional fue aprobado por la Autoridad (entonces CIVIT) a propuesta del Departamento de la Función Pública, a la luz de las directrices contenidas en las Orientaciones del Comité Interministerial. Tras la reforma de los poderes de la Autoridad, en 2014, la adopción del nuevo Plan es un acto autónomo de la ANAC, incluso si se desarrolla a través de procesos participativos y en colaboración con otras instituciones.

35 Como se afirma en la Circular núm. 1/2013 del Departamento de la Función Pública, «La razón que subyace a esta decisión es que se considera la función de responsable de la prevención como "naturalmente complementaria" de las competencias generales que le corresponden por ley al secretario, quien, según el art. 97 del Decreto Legislativo núm. 267 de 2000, "lleva a cabo tareas de colaboración y funciones de asistencia jurídica y administrativa en relación con los órganos de la entidad en el cumplimiento de la acción administrativa contemplada en la ley, los estatutos y los reglamentos"». 
indicaciones organizativas, las formas de aplicación de las obligaciones de transparencia previstas por la ley y las medidas de transparencia adicionales); y el código de conducta, que contiene los deberes de los funcionarios públicos. Todos estos instrumentos están vinculados en la lógica de la prevención de riesgos que caracteriza a los planes: dado un cierto riesgo, puede ser contrarrestado a través de diferentes medidas, y al plan trienal le corresponde identificar la medida considerada mejor y más eficaz. Las decisiones tomadas en los planes se verifican y mejoran año tras año, pero sobre todo se ponen «a prueba» a través de la experiencia: un episodio de corrupción, una condena por una mala gestión de los recursos públicos o unas medidas disciplinarias por incumplimiento de los deberes de los funcionarios implicarán la necesidad de revisar y reforzar las medidas preventivas. Por su parte, en particular, ante un caso de corrupción, el responsable de la prevención tendrá que demostrar que se han tomado las medidas necesarias para evitar riesgos «conocidos» o predecibles.

La persona encargada de la prevención, que constituye el perno interno del sistema de prevención de la corrupción y está en relación constante con la ANAC y con sus líneas directrices, cuenta con la asistencia de los directivos (responsables de supervisar la aplicación de las distintas medidas en las estructuras y por el personal que dirigen) y, en particular, de algunas figuras de referencia (los «referentes») en las áreas principales de acción administrativa. Normalmente, la persona encargada de la prevención de la corrupción también actúa como gestor de la transparencia, esto es, el responsable de supervisar el cumplimiento de las obligaciones de publicación, y por lo tanto de su correspondiente «programa» (que es una sección del plan de prevención).

En los cinco años transcurridos desde la Ley núm. 190, y en particular a través del primer plan nacional, sus actualizaciones, y ahora el nuevo plan nacional, la ANAC ha adquirido una experiencia importante y su enfoque ha cambiado gradualmente. Si el primer plan refleja un sistema de tipo metodológico y tiene una función en primer lugar de orientación en relación con las administraciones para la introducción de un instrumento innovador, los documentos más recientes escogen enfoques más específicos, de tipo sectorial o con respecto a los tipos específicos de administraciones.

Las administraciones son profundamente diferentes entre sí y requieren enfoques diferenciados: así se entienden las «especificaciones» relativas, por ejemplo, a las áreas presentes en todas las administraciones, como la de los contratos, o a sectores específicos, como la sanidad o la administración del suelo ${ }^{36}$, o a tipos de administración, tales como los pequeños ayuntamientos, las áreas metropolitanas, los colegios profesionales ${ }^{37}$ o las empresas subsidiarias y controladas por organismos públicos. En otras ocasiones, constituyen motivo de atención reforzada herramientas específicas que la ANAC pretende poner en valor o impulsar, en ocasiones mediante directrices especiales, retomadas después en el Plan Nacional, como en el caso de la institución de la whistleblowing ${ }^{38}$, o denuncia de irregularidades, o directamente a través del Plan, como en el caso de la rotación de personal ${ }^{39}$. Todas las intervenciones están vinculadas a la actividad constante de supervisión que lleva a cabo la Autoridad sobre la aprobación de los planes y, aunque solo sea a través de un muestreo o bajo indicación, de su misma calidad ${ }^{40}$.

\section{EL FORTALECIMIENTO DE LA IMPARCIALIDAD DE LOS FUNCIONARIOS: CONFLICTOS DE INTERESES Y NORMAS DE CONDUCTA}

Entre las medidas de prevención de la corrupción que ya están reguladas en la Ley núm. 190 y en decretos ejecutivos posteriores, en primer lugar nos encontramos con mecanismos destinados a reforzar

36 El Plan Nacional de Lucha Contra la Corrupción de 2016 dedica especial atención también a la protección y promoción del patrimonio cultural; y cabe destacar que una sección específica dedicada a la «sanidad» ya estaba prevista en la actualización de 2015 del primer Plan Nacional de Lucha Contra la Corrupción, que también se centró en el sector de los contratos públicos.

37 El nuevo Plan Nacional de Lucha Contra la Corrupción de 2016 contiene secciones específicas dedicadas precisamente a los pequeños ayuntamientos, las áreas metropolitanas y los colegios y asociaciones profesionales, así como a los centros educativos.

38 La Autoridad aprobó la Resolución núm. 6, de 28 de abril 2015, de directrices en materia de protección del empleado público que denuncia abusos, que luego se retomó íntegramente en el Plan Nacional de Lucha Contra la Corrupción de 2016 (punto 7.5 ).

39 En el ámbito del PNLCC la rotación del personal es vista con buenos ojos, porque se «considera una medida preventiva y organizativa destinada a limitar la consolidación de las relaciones que pueden alimentar dinámicas indebidas en la gestión administrativa, como consecuencia de la permanencia a lo largo del tiempo de ciertos empleados en el mismo cargo o función» (véase en este sentido, el Plan Nacional de Lucha Contra la Corrupción de 2016, punto 7.2). El Plan se detiene en los mecanismos de «rotación ordinaria» (así como la «extraordinaria» en los casos de corrupción), de acuerdo con el art. 1, apartado 4, letra e) de la Ley 190/2012, que establece que le corresponde a la ANAC definir los criterios que deben seguir las administraciones para garantizar la rotación de los directivos en los sectores especialmente expuestos a la corrupción.

40 Informe sobre el estado de la aplicación y la calidad de los planes trienales de prevención de la corrupción en las administraciones públicas 2015-2017, de la Autoridad Nacional de Lucha Contra la Corrupción, de 16 de diciembre de 2015, en www.anticorruzione.it, pág. 3. 
la «imparcialidad objetiva» actuando sobre las características de las organizaciones y las decisiones de identificación de los responsables de los órganos de gestión. Es un enfoque que en su conjunto constituye una característica particular de la experiencia italiana, a partir de una decisión (reafirmada y reforzada por el sistema de la ley de lucha contra la corrupción) de contemplar una «distinción» de funciones y responsabilidades entre los órganos políticos, responsables de los actos de dirección de la acción administrativa y los órganos burocráticos y profesionales (Ios directivos), responsables de los actos de gestión y, por tanto, de las medidas «puntuales» dirigidas a los ciudadanos.

Esta decisión, que se va imponiendo en Italia tras los escándalos de «Manos Limpias», la famosa historia de corrupción que afecta a una parte importante del sistema político a principios de los años 90 del siglo pasado, tenía la intención de «alejar» la política de la relación directa con los intereses, creando un sistema más transparente (de actos de gestión guiados por actos formales de orientación), menos arbitrario y menos vinculado a consideraciones políticas o de partido.

Este modelo se ha confirmado e incluso reforzado a través de medidas destinadas a garantizar una «justa distancia» entre el gestor público y las funciones políticas activas mediante un régimen llamado de «inadecuación de los nombramientos»: no podrá aceptar cargos directivos o de responsabilidad en los organismos públicos o las entidades de control público quien haya desempeñado cargos políticos recientemente.

El asunto se rige por uno de los decretos legislativos ejecutivos de la Ley núm. 190 antes mencionado, el Decreto Legislativo núm. 39 de 2013, aprobado por el Gobierno Monti casi al final de su experiencia.

En retrospectiva, es uno de los pocos casos en los que, aunque de manera indirecta, el sistema de lucha contra la corrupción no solo atiende al personal burocrático sino también al político. Responde a una exigencia similar, la de evitar situaciones de «confusión» entre diferentes funciones, la aplicación de una medida análoga, con la necesidad de un «período de enfriamiento», para el personal público con respecto a su actividad de procedencia (o de destino) en relación con sujetos privados supervisados por la administración o con los que la administración, y el departamento específico, tenga relaciones contractuales o constantes. El mismo mecanismo (pero aquí por diferentes razones, para garantizar la integridad de los funcionarios) actúa ante la existencia de condenas anteriores, en particular por delitos contra la administración pública.

En una perspectiva análoga, de protección de la administración, en términos generales y preventivos, respecto de situaciones de posibles conflictos de intereses, la ley regula cuidadosamente otro mecanismo, el de las incompatibilidades. De acuerdo con el mismo Decreto núm. 39, están reguladas en una serie, bastante numerosa, de casos de incompatibilidad: mientras que el mecanismo de «inadecuación de los nombramientos» es una novedad en la experiencia italiana, aunque pueda estar relacionada con las regulaciones de los límites post employment o de limitación de las puertas giratorias, el de las incompatibilidades se encuentra tradicionalmente presente en el sistema italiano, y la novedad es en este caso su proyección clara como una herramienta anticorrupción, así como su ampliación a muchos nuevos casos ${ }^{41}$.

Por lo tanto, la lógica es, en cualquier caso, limitar por encima de todo los conflictos de intereses, en situaciones consideradas menos "graves» respecto de las que conllevan una inadecuación del nombramiento: así, se incluyen los cargos directivos que que implican poderes de supervisión sobre las entidades privadas controladas o financiadas, son incompatibles con la aceptación y el ejercicio, durante el desempeño del cargo, de tareas y cargos en esas mismas entidades. La ley regula en cualquier caso un gran número de situaciones de incompatibilidad entre funciones y cargos: se consideran los casos de incompatibilidad entre cargos ejecutivos en las empresas sanitarias y el ejercicio de actividades profesionales o de cargos en entidades privadas reguladas o financiados por el Servicio Regional de Salud; los supuestos, variados, de incompatibilidad entre las funciones directivas y de administración de una entidad pública y los cargos «políticos» a nivel estatal, regional y local; los supuestos de incompatibilidad entre la función de administrador de una entidad privada de control público y cargos políticos a nivel estatal, regional y local.

La lógica que parece unir las diferentes situaciones, consideradas de mayor riesgo (y, por lo tanto, que justifican un régimen de «inadecuación de los nombramientos» más gravoso y con períodos de enfriamiento, por regla general de uno o dos años) o de menor riesgo pero aun así significativo (y, por lo tanto, sujetas a incompatibilidades), es la prevención de conflictos de interés. Son, sin embargo, mecanismos definidos en

41 Acerca de estas instituciones, en conjunto, cfr. B. PONTI, "La regolazione dell'accesso agli incarichi esterni da parte dei dipendenti dopo la legge 190/2012: evoluzione del sistema e problemi di applicazione agli enti territoriali”, en Istituzioni del federalismo, 2013, págs. 409 y ss.; F. MERLONI, "Nuovi strumenti di garanzia dell'imparzialità degli amministratori: I'inconferibilità e incompatibilità degli incarichi”, en La legge anticorruzione, cit., 196-209; D. ANDRACCHIO, "Il divieto di 'pantouflage': una misura di prevenzione della corruzione nella pubblica amministrazione”, en GiustAmm.it, 2016, núm. 9, págs. 1-10. 
el ámbito legislativo y, como tales, «rígidos», ya que nada excluye que las administraciones puedan definir, con sus propias normas y en respuesta a «riesgos» específicos advertidos en el Plan, nuevos supuestos de incompatibilidad.

Otro elemento, todavía más importante, del sistema de instrumentos e prevención está representado por los «códigos de conducta»: una institución que en la experiencia italiana tiene ya casi quince años de existencia, y que fue previsto por primera vez en 1993, pero que se ha rediseñado por completo con la ley de lucha contra la corrupción. La Ley 190, de hecho, ha reescrito el art. 54 del Decreto Legislativo núm. 165 de 2001 (Texto Refundido del Empleo en las Administraciones Públicas ${ }^{42}$ ), introduciendo una serie de elementos altamente innovadores.

En términos generales, el código de conducta es una lista de los deberes establecidos unilateralmente por el gobierno y luego detallada y complementada por un documento similar adoptado por cada administración, destinados a garantizar la imparcialidad del empleado público y el adecuado desempeño de las funciones asignadas. De alguna manera, es la explicitación de ese «estatuto constitucional» que califica al empleado de las administraciones públicas ${ }^{43}$ : un empleado al servicio del interés general (está «al servicio exclusivo de la Nación» ${ }^{44}$ ), obligado a garantizar la imparcialidad ${ }^{45}$, actuar con fidelidad y «con disciplina y honor ${ }^{46}$. Estos valores constitucionales se traducen, en resumen, en una serie de deberes que constituyen su manifestación y especificación ${ }^{47}$ : unos deberes que, a diferencia de las obligaciones más estrictamente pertinentes desde el punto de vista del desempeño laboral, están vinculados al cuidado de las funciones públicas y se sustraen a las reglas contractuales, pues están reservados a una fuente de derecho público ${ }^{48}$.

El código de conducta se introduce, por tanto, en un «entorno» por lo general regulado por acuerdos contractuales y por lo tanto "privatizado», e indica la especialidad del empleo con las administraciones públicas $^{49}$ : este elemento público, sin embargo, forma parte de manera nada sencilla del sistema de las obligaciones contractuales y de su correspondiente «código disciplinario». Se trata de temas complejos, que han hecho poco efectivo e ineficaz el instrumento en los años anteriores a la reforma, especialmente en términos de aplicabilidad de sanciones disciplinarias. La reforma de 2012 interviene, pues, afirmando con fuerza, en primer lugar, el valor, en términos de responsabilidad disciplinaria, de los deberes definidos en los códigos de conducta (ya sea el código general, nacional, o los «complementario» aprobados por cada administración): el incumplimiento de los deberes puede dar lugar a sanciones disciplinarias que van hasta el despido en caso de conducta particularmente grave o reiterada ${ }^{50}$.

La otra innovación importante, que ya se ha mencionado, está constituida por la opción de articular un sistema de deberes en dos niveles: el nivel nacional, con un código de conducta común para todos los empleados (este código fue aprobado por el Decreto Presidencial núm. 62 de 2013) y luego por códigos adicionales, especiales y «descentralizados», propios de cada administración. Estos códigos del segundo nivel tienen el mismo valor que el código nacional, y cada administración tiene que adoptar esta herramienta que es, especialmente en este nivel, una medida importante de prevención de la corrupción y por lo tanto

42 Decreto Legislativo núm. 165, de 30 de marzo de 2001, por el que se aprueban normas generales de ordenamiento del empleo en las administraciones públicas (G. U. núm. 106 del 9 de mayo de 2001).

43 Cfr. G. SIRIANNI, "I profili costituzionali. Una nuova lettura degli articoli 54, 97 e 98 della Costituzione", en F. MERLONI, L. VANDELLI (eds.), La corruzione amministrativa. Cause, prevenzione, rimedi, Florencia, Passigli, 2010 , págs. 129 y ss.; en general, F. MERLONI, R. CAVALLO PERIN (eds.), Al servizio della Nazione, cit.

44 Art. 98 de la Constitución Italiana, apartado 1, «Los empleados públicos están al servicio exclusivo de la Nación».

45 Art. 97, apartado 2, «Las oficinas públicas están organizadas de acuerdo a la ley, de modo que garanticen la eficiencia y la imparcialidad de la administración»: la disposición constitucional está dirigida al legislador y a la organización, pero plantea una principio de que tiene valor también subjetivo para el funcionario.

46 En virtud del art. 54, además de la obligación de «lealtad a la República», que correspondo a todos los ciudadanos (apartado 1 ), «Los ciudadanos encargados de las funciones públicas tienen el deber de llevarlas a cabo con disciplina y honor, prestando juramento en los casos establecidos por la ley» (apartado 2).

47 B. G. MATTARELLA, Le regole dell'onestà. Bolonia: II Mulino (2007); F. MERLONI, R. CAVALLO PERIN (eds.), Al servizio della Nazione. Milán: Franco Angeli (2008)

48 Cfr. recientemente E. D'AVINO, 'L'imperfetta contrattualizzazione del lavoro pubblico nel prisma della disciplina anticorruzione”, en II Lavoro nelle pubbliche amministrazioni, 2015, fasc. 2, págs. 285 y ss.

49 E. CARLONI, "Il nuovo Codice di comportamento ed il rafforzamento dell'imparzialità dei funzionari pubblici", en Istituzioni del federalismo, 2013, págs. 377 y ss.; F. MERLONI, "Codici di comportamento", en // Libro dell'anno del diritto, Roma, Treccani, 2014; F. MERLONI, I piani anticorruzione e i codici di comportamento, cit., págs. 4 y ss.; véase, de nuevo, B. G. MATTARELLA, "I codici di comportamento", en Rivista giuridica del lavoro, 1996, págs. 275 y ss.; E. CARLONI, "Ruolo e natura dei c.d. 'codici etici' delle pubbliche amministrazioni", en Diritto pubblico, 2002, 319-361.

50 E. CARLONI, "II nuovo Codice di comportamento ed il rafforzamento dell'imparzialità dei funzionari pubblici", cit., págs. 377 y ss.; E. D'ALTERIO, “I codici di comportamento e la responsabilità disciplinare”, en La legge anticorruzione, cit., págs. 25 y ss. 
debería satisfacer no solo las características específicas de cada tipo de administración, sino también las características de cada entidad pública en términos de su contexto interno y externo.

La Autoridad Nacional de Lucha Contra la Corrupción vela por la adopción efectiva del código por parte de las distintas administraciones (que no solo debe reproducir, como a veces ha ocurrido, el código nacional o «copiar» el código de otras administraciones), incluso con poderes de sanción, y supervisa su aplicación ${ }^{51}$.

\section{LA TRANSPARENCIA ADMINISTRATIVA MEDIANTE LA OBLIGACIÓN DE PUBLICACIÓN}

La principal medida preventiva, no obstante, en la aplicación general de la reforma, es en primer lugar la transparencia administrativa: desde hace ya mucho tiempo se ha consolidado la idea de que «la luz del sol» es el mejor desinfectante ${ }^{52}$ y esta idea está ciertamente presente en el diseño trazado por la Ley núm. 190 de 2012. La legislación italiana es, en este aspecto, particularmente interesante: caracterizada tradicionalmente por una idea de la transparencia que coincide con el derecho de acceso a los documentos previsto por la Ley de Procedimiento Administrativo (núm. 241 de 199053), ha evolucionado progresivamente a un papel cada vez más relevante de las obligaciones de publicación, aplicadas mediante la difusión de información a través de los sitios web de las administraciones públicas ${ }^{54}$.

El punto de inflexión normativo, que hizo posible esta evolución, se sitúa en el Código de Administración Digital: la ley sobre la digitalización de la administración pública, Decreto Legislativo núm. 82 de $2005^{55}$, ha establecido la obligación de todas las administraciones de crear un sitio web institucional y define sus características, además de proporcionar una serie de primeros contenidos obligatorio (contenido esencialmente organizativo y de servicios: los tipos de procedimientos, sus términos y su responsables, etc. ${ }^{56}$. También en 2005 , la Ley núm. 15 de $2005^{57}$, que modificó el derecho de acceso a los documentos clarificando su función esencialmente como garantía para la protección de los sujetos afectados y no para el control generalizado de la acción pública. Las exigencias de control generalizado que no se satisfacen mediante el derecho de acceso están empezando a poderse realizar cada vez más a través de la publicación de la información en los sitios institucionales, y en este sentido se orientan muchas previsiones puntuales y, por consiguiente, de una manera más consciente y sistemática, la reforma de 2009 promovida por el ministro Brunetta ${ }^{58}$.

La ley de lucha contra la corrupción desarrolla de forma todavía más completa este proyecto, definiendo una serie de obligaciones adicionales de publicación y en especial con la delegación al gobierno para elaborar un «texto refundido» que contenga todas las obligaciones de publicación ya establecidas por la ley. Esta medida, también conocida como "código de transparencia», fue aprobada en 2013 (decreto legislativo núm. 33) y se caracteriza esencialmente por dos elementos: por un lado, un régimen orgánico que acompaña a las obligaciones de publicación, y por otro, una extensa lista de obligaciones de publicación relativas a distintos aspectos (la organización, el personal, los actos y las actividades, el uso de los recursos, los servicios públicos, áreas específicas de acción), todos identificados como rele-

51 En este sentido se pronuncia el "Reglamento en materia del ejercicio del poder sancionador de la Autoridad Nacional de Lucha Contra la Corrupción por el incumplimiento de la adopción de los planes trienales de prevención de la corrupción, los programas trienales de transparencia y de los códigos de conducta", de 9 de septiembre de 2014.

52 W. BRANDEIS, Other people's money - And how the bankers use it, 1914, en http://www.law.louisville.edu; cfr. en un sentido parecido ANAC, Relazione Annuale al Parlamento dell'Autorità Nazionale Anticorruzione per l'anno 2015, cit., pág. 5.

53 Ley núm. 241, de 7 de agosto de 1990, de nueva normativa sobre el procedimiento administrativo.

54 E. CARLONI, "La casa di vetro e le riforme. Modelli e paradossi della trasparenza amministrativa", en Diritto pubblico, 2009, págs. 779 y ss.; C. Cudia, "Trasparenza amministrativa e pretesa del cittadino all'informazione", en Diritto pubblico, 2013, págs. 99 y ss.; D.-U. GALETTA, Transparency and access to public sector information in Italy: a proper revolution? cit., págs. 213 y ss.

55 Decreto Legislativo núm. 82, de 7 marzo de 2005, por el que se aprueba el Código de la Administración Digital: el código de la administración digital (CAD) ha sido modificado en varias ocasiones, la última en el contexto de las reformas «Madia», por el Decreto Legislativo núm. 179 de 26 de agosto de 2016. Sobre la configuración inicial del Código, cfr. E. CARLONI (ed.), Codice dell'amministrazione digitale, Rímini, Maggioli, 2005.

56 E. CARLONI, 'Nuove prospettive della trasparenza amministrativa: dall'accesso ai documenti alla disponibilità delle informazioni”, en Diritto pubblico, 2005, págs. 573 ss.

57 Ley núm. 15, de 11 febrero de 2005, por la que se aprueban cambios y adiciones a la Ley núm. 241, de 7 de agosto de 1990, sobre normas generales de la acción administrativa (G. U. núm. 42 de 21 de febrero de 2005).

58 Cfr. A. BONOMO, Informazione e pubbliche amministrazioni. Dall'accesso ai documenti alla disponibilità delle informazioni, Bari, Cacucci, 2012. 
vantes en la perspectiva de un control generalizado y, por lo tanto, con el objetivo de prevenir y combatir la corrupción ${ }^{59}$.

En consonancia con este enfoque, la Autoridad de Lucha Contra la Corrupción tiene la función de supervisar el cumplimiento de las obligaciones de publicación, a través de los informes del gerente de la transparencia y del responsable de la prevención de la corrupción, presentes en todas las administraciones. Por lo tanto, la ANAC está cualifica como una autoridad de la transparencia, además de la prevención de la corrupción, aunque sea con referencia a este instrumento específico de transparencia «proactiva».

En respuesta a las críticas generalizadas, que se quejaban desde diferentes ángulos de la limitada utilidad de este mecanismo de transparencia o de la carga excesiva para las administraciones (y la compresión excesiva de la privacidad de los individuos involucrados en la publicación en los sitios de información que les afectan ${ }^{60}$ ), el legislador ha «retocado» recientemente esta normativa con un decreto de 2016 que forma parte de las reformas llevadas a cabo por el Gobierno Renzi y, por tanto, por la Ministra de Administraciones Públicas, Madia. La denominada ley «Madia», núm. 124 de 2015, delegó al gobierno para revisar el Decreto Legislativo núm. 33 y esta delegación fue aplicada mediante el Decreto Legislativo núm. 97 de 2016. Como sucede a menudo en las reformas italianas de los últimos años, sin embargo, el mismo decreto 97 es susceptible de ser modificado, en el plazo de un año después de su entrada en vigor, con los correspondientes decretos correctivos ya previstos en la delegación original: este marco, tan complejo y «móvil», hace que sea objetivamente difícil lidiar con esta reforma, así como con otras reformas de la administración pública italiana.

Desde el punto de vista de las obligaciones de publicación, las innovaciones introducidas por el Decreto Legislativo núm. 97 deben ser considerados globalmente limitadas y no modifican el sistema de la legislación: la principal (y decisiva) novedad, sin embargo, es la decisión de introducir junto a las obligaciones de publicación de un nuevo y adicional mecanismo de transparencia, sobre el que es necesario detenerse con cierta atención, un derecho de acceso «generalizado» (reconocido a todo el mundo) que complementa al tradicional derecho de acceso a los documentos y las más recientes obligaciones de publicación, conformando un panorama articulado de instrumentos para asegurar la capacidad de conocer la acción pública.

Por lo tanto, la transparencia debe entenderse, en el diseño del Decreto Legislativo núm. 33, modificado por las más recientes medidas, «como la accesibilidad total de los datos y documentos en poder de las administraciones públicas, con el fin de proteger los derechos de los ciudadanos, promover la participación de los interesados en la actividad administrativa y fomentar formas generalizadas de control sobre el cumplimiento de las funciones institucionales y sobre la utilización de los recursos públicos» ${ }^{61}$ : estas distintas exigencias se realizan principalmente a través de las obligaciones de publicación, así como a través del nuevo derecho de acceso «generalizado».

Ante la obligación de publicación, cualquier persona tiene un «derecho al conocimiento» ${ }^{62}$ : a la publicación en los sitios web institucionales de las administraciones públicas de los documentos, la información y los datos «le corresponde el derecho de toda persona a tener acceso a los sitios de manera directa e inmediata, sin necesidad de autenticación e identificación». Son informaciones, documentos y datos sometidos a un sistema de «transparencia total»: estos datos «son públicos y cualquier persona tiene el derecho a conocerlos, disfrutar de ellos de forma gratuita y utilizarlos y reutilizarlos». Se trata, de nuevo, de datos a los que se debe asegurar una «calidad» adecuada, entendida como «integridad, actualización constante, exactitud, oportunidad, facilidad de consulta, comprensibilidad, homogeneidad, fácil accesibilidad, así como conformidad con los documentos originales en poder de la administración, la indicación de su origen y su reutilización».

59 E. CARLONI, L'amministrazione aperta. Regole, strumenti, limiti dell'open government, Rímini, Maggioli, 2014; B. PONTI (ed.) La trasparenza amministrativa dopo il d.Igs. 14 marzo 2013, núm. 33. Maggioli: Rimini (2013). Cfr. M. SAVINO, "Le norme in materia di trasparenza amministrativa e la loro codificazione", en La legge anticorruzione cit., 113-123; A. BONOMO, "Il codice della trasparenza e il nuovo regime di conoscibilità dei dati pubblici", en Istituzioni del federalismo, 2013, págs. 725 ss.; G. GARDINI, "II codice della trasparenza: un primo passo verso il diritto all'informazione amministrativa?", en Giornale di diritto amministrativo, 2014 , págs. 875 ss.; A. Natalini, G. Vesperini (eds.), I/ Big Bang della trasparenza, Nápoles, Editoriale Scientifica (2015).

60 Cfr. Garante per la protezione dei dati personali, "Linee guida in materia di trattamento di dati personali, contenuti anche in atti e documenti amministrativi, effettuato per finalità di pubblicità e trasparenza sul web da soggetti pubblici e da altri enti obbligati”, 2014, en www.garanteprivacy.it; L. CALIFANO, "Trasparenza e privacy: la faticosa ricerca di un bilanciamento mobile", en L. CALIFANO, C. COLAPIETRO, C. (eds.), Le nuove frontiere della trasparenza nella dimensione costituzionale, Nápoles, Editoriale scientifica, 2015, págs. 35 y ss.

61 Así se dispone en el artículo 1, "Principio general de transparencia".

62 Véase el art. 3, "Publicidad y derecho al conocimiento"; cfr. C. CUDIA, "Pubblicità e diritto alla conoscibilità", en B. PONTI (ed.), Nuova trasparenza amministrativa e libertà di accesso alle informazioni, Rímini, Maggioli, 2016, págs. 93 y ss. 
En esencia, mediante la definición de cierta información como sujeta a la obligación de publicación, el legislador define un área de cognoscibilidad plena, que también está garantizada por la existencia de políticas de aplicación, de responsabilidades específicas, así como de la supervisión de la autoridad de lucha contra la corrupción. Para garantizar la correcta aplicación de las obligaciones de publicación, el legislador prevé también un derecho específico de tipo instrumental dirigido al ciudadano, llamado «acceso cívico»: «la obligación establecida en la normativa vigente y que corresponde a las administraciones públicas de publicar documentos, información o datos implica el derecho de toda persona a solicitar los mismos, en los casos en los que se haya omitido su publicación». Por lo tanto, es una posición subjetiva simétrica, y correspondiente, a las obligaciones de publicación y que sirve esencialmente para «forzar» su cumplimiento efectivo.

\section{EL NUEVO DERECHO GENERAL DE ACCESO}

Este modelo de publicidad del tipo «proactivo» se ha completado e integrado recientemente con un tipo mecanismo e cognoscibilidad de tipo «reactivo», inspirado en la experiencia de matriz estadounidense de la «Freedom of Information Act» ${ }^{63}$. Precisamente a partir del «modelo de la FOIA», que como se sabe ha tenido un éxito y una difusión global, la reforma «Madia» quiso introducir una «libertad de información» (art. 7, apartado 1, letra h) de la Ley 124 de 2015: el gobierno ha sido delegado, por tanto, para introducir el «reconocimiento de la libertad de información a través del derecho de acceso, incluso por medios telemáticos, de cualquier persona, independientemente de las situaciones jurídicamente relevantes, a los datos y los documentos en poder de las administraciones públicas [...] con el fin de promover formas generalizadas de control sobre el cumplimiento de las funciones institucionales y sobre la utilización de los recursos públicos».

En respuesta a este mandato, por lo tanto, se aprobó, como ya se ha mencionado, el Decreto Legislativo núm. 97 de 2016, que introdujo esta «libertad de información», bajo la forma de un «acceso generalizado», que se une en el texto del reformado Decreto Legislativo núm. 33 al «viejo» acceso cívico, ambos a su vez regidos por el art. $5^{64}$. El resultado es un marco de lectura nada fácil, puesto que coexisten un derecho de acceso cívico que, como se ha visto, está vinculado a las obligaciones de publicación (y por lo tanto no sujeto a los límites previstos en el apartado 1 del art. 5) y un nuevo derecho de acceso «generalizado» (como ahora se define cada vez más en la doctrina y en las medidas ejecutivas, aunque este término no está en el texto legislativo), dispuesto en el apartado 2 posterior ${ }^{65}$.

Esta disposición establece, en efecto, que «con el fin de fomentar las formas generalizadas de control sobre el cumplimiento de las funciones institucionales y sobre la utilización de los recursos públicos y para fomentar la participación en el debate público, todo el mundo tiene el derecho a acceder a la información y los documentos en poder de las administraciones públicas, además de aquellos publicados de acuerdo con este decreto, en el respecto de los límites impuestos por protección de los bienes jurídicos relevantes». Dichos límites se abordan en el artículo 5 bis.

El escenario descrito por la introducción de la nueva «FOIA» italiana parece interesante a primera vista: a las obligaciones de publicación se une, siempre con el objetivo de control generalizado, así como de participación en el debate público, un mecanismo capaz de «iluminar» incluso las áreas no sujeta a las obligaciones de publicación ${ }^{66}$. El marco legislativo, sin embargo, se caracteriza por un conjunto de límites amplios y bastante genéricos, así como no exhaustivos ya que el apartado 3 del artículo 5 bis se abre a límites adicionales establecidos por ley con una formulación vaga y susceptible de interpretaciones especialmente

63 Acerca del «éxito» del modelo estadounidense y de su difusión, J. M. ACKERMAN, I. E. SANDOVAL-BALLESTEROS, "The global explosion of Freedom of Information Laws", en Administrative Law Review (2006) 85-130; OCDE, The right to open public administrations in Europe: emerging legal standards, ed. M. SAVINO, 46 Sigma Paper (2010).

64 Para un marco inicial, con diferentes interpretaciones, cfr. B. PONTI, "La trasparenza e i suoi strumenti: dalla pubblicità all'accesso generalizzato", en Id. (eds.), Nuova trasparenza amministrativa e libertà di informazione, cit.; la idea de que la nueva libertad de información constituye el nuevo y principal instrumento de transparencia ha sido establecido de manera particularmente marcada por M. SAVINO, "II FOIA italiano. La fine della trasparenza di Bertoldo", en Giorn. dir. amm., 2016, págs. 593 y ss.

65 Cf. B. PONTI (ed.), Nuova trasparenza amministrativa e libertà di accesso alle informazioni, Rímini, Maggioli, 2016. Sobre ello cfr. E. CARLONI, F. GIGLIONI, "Three transparencies and the persistence of opacity in the Italian government system", en European public law, 2017, núm. 2; G. GARDINI, "Il paradosso della trasparenza in Italia. L'arte di rendere complesse le cose semplici", en Federalismi.it, núm. 1, 2017, pág. 1; S. VILLAMENA, "Il c.d. FOIA (o accesso civico 2016) ed il suo coordinamento con istituti consimili", en Federalismi.it, núm. 23/2016.

66 Considera de manera especialmente positiva el nuevo enfoque D.-U. GALETTA, "The Italian Freedom of information act 2016 (why transparency-on-request is a better solution)”, en Italian Journal of Public Law, 2016, núm. 2. 
extensas. Los límites se expresan sustancialmente en los tres apartados del artículo 5 bis: límites relativos, para garantizar el interés público; límites relativos, para garantizar los intereses privados; límites «absolutos». En los primeros dos «bloques» de límites, el acceso es «rechazado si la denegación es necesaria para evitar un perjuicio real para la protección de uno de los siguientes intereses».

Corresponde a la ANAC, aunque de acuerdo con la Autoridad Garante de la Protección de los Datos Personales (que en general desempeña un papel central en el diseño general de la nueva institución), definir y «contener» el alcance de estos límites: de acuerdo con el apartado 6 del art. 5 bis, «para la definición de las exclusiones y limitaciones en el acceso cívico previsto en el presente artículo, la Autoridad Nacional de Lucha Contra la Corrupción, en consulta con la Autoridad Garante de la Protección de los Datos Personales [...] adopta directrices que establecen indicaciones operativas». Estas directrices han sido adoptadas ${ }^{67}$ y tienen elementos ambivalentes: en cualquier caso, está bien construido el mecanismo de equilibrio del «test del equilibrio». Sin embargo, en términos generales, los resultados del primer seguimiento ${ }^{68}$ parecen indicar una falta de eficacia de este mecanismo, con la tendencia generalizada de las administraciones de denegar el acceso, aprovechándose de unos los límites tan amplios, o incluso no respondiendo las solicitudes de acceso aprovechándose de la debilidad de los mecanismos de garantía del cumplimiento.

Precisamente por estas razones en el plano político se discute la necesidad de una "puesta a punto» del marco legislativo, pero también se propone la aprobación por parte del Ministerio de Administraciones Públicas de una circular ${ }^{69}$, dirigida a las administraciones del Estado, para fomentar una mayor atención a la exigencia de hacer efectivo y eficaz de este derecho de acceso generalizado. Una opción, esta última, que, sin embargo, presenta otros aspectos problemáticos, entre los que se encuentra el riesgo de una superposición de esta circular con las directrices de la ANAC y una duplicación de las funciones de «guía» de la transparencia (revisando y regresando a las decisiones acerca de la demarcación clara entre la ANAC y el Ministerio del decreto núm. 90 de 2014).

\section{LA NUEVA NORMATIVA DE CONTRATACIÓN PÚBLICA}

Es este un panorama, como se puede ver, muy amplio y articulado, que también consta de la nueva normativa sobre contratos públicos y, por tanto, del papel de la Autoridad Anticorrupción como autoridad de supervisión de la cuestión: una vertiente nada secundaria de la acción de la ANAC y de la estrategia global para hacer frente a la corrupción ${ }^{70}$. En este contexto, el sistema delineado a partir de las recientes reformas (el nuevo código de contratos públicos, Decreto Legislativo núm. 50 de $2016^{71}$ ) y de las más recientes aún (el decreto correctivo núm. 56 de 2017) tiene una serie de elementos de interés. Se trata de una intervención reguladora particularmente amplia, tanto por las disposiciones situadas directamente en el nivel legislativo como por las posteriores medidas de regulación general adoptadas por la misma Autoridad de Lucha Contra la Corrupción, que es imposible describir en unas pocas líneas. Cabe señalar, no obstante, sin pretensión de ser exhaustivos, los elementos que parecen más significativo desde el punto de vista de las políticas de prevención de la corrupción.

En primer lugar, precisamente en relación con la necesidad de proteger el sector de los contratos públicos, cabe destacar la decisión del legislador italiano, incluso antes del nuevo código de contratos, de concentrar en una sola autoridad independiente la materia de la lucha contra la corrupción y la contratación pública.

\footnotetext{
67 "Directrices que contienen las indicaciones operativas para la definición de las exclusiones y límites del acceso cívico establecido en el art. 5, apartado 2 del Decreto Legislativo 33/2013", Resolución núm. 1.309 de la Autoridad Nacional de Lucha Contra la Corrupción (G. U. núm. 7 de 10 de enero 2017).

68 En particular, acerca del primer seguimiento "oficial, del Departamento de la Función Pública: $h$ ttp://www.funzionepubblica.gov. it/articolo/riforma-della-pa/02-05-2017/foia-primo-monitoraggio-del-dipartimento-della-funzione.

69 El proyecto de esta circular fue puesto a disposición para su consulta el 12 de mayo de 2017: véase en http://open.gov.it/ consultazionefoia/

70 G. M. RACCA, "La prevenzione e il contrasto della corruzione nei contratti pubblici (art. 1, commi 17-25, 32 e 52-58)", en B. G. MATTARELLA, M. PELISSERO (eds.), La legge anticorruzione, cit., esp. págs. 101-102; G. M. RACCA, "Dall'Autorità sui contratti pubblici all'Autorità Nazionale Anticorruzione: il cambiamento del sistema", en Diritto amministrativo, 2015, fasc. 2-3, págs. 345 y ss.

71 Entre los numerosos comentadores de la reforma, cfr. las eficaces observaciones de L. TORCHIA, "III nuovo Codice dei contratti pubblici: regole, procedimento, processo. Commento a d.Ig. 18 aprile 2016, núm. 50”, en Giornale di diritto amministrativo, 2016, fasc. 5, págs. 605 y ss.; y más ampliamente, entre otros, R. DE NICTOLIS, "Il nuovo codice dei contratti pubblici. Commento a d.Ig. 18 aprile 2016, núm. 50", en Urbanistica e appalti, 2016, fasc. 5, págs. 503 y ss.; M. CASAVECCHIA, G. REDI, “II Nuovo Codice degli appalti pubblici: novità per l'affidamento dei lavori e dei servizi", en II Nuovo Diritto delle Società, 2017, págs. 7 y ss.
} 
En segundo lugar, a través de la rica base de datos de que dispone, desde hace tiempo ${ }^{72}$ la autoridad en materia de contratos puede llegar a un conocimiento de las «anomalías» y, en consecuencia, comprender por lo menos en parte las situaciones de riesgo específicas: en este sentido, el sector de los contratos públicos es el primero para el que la Autoridad ha desarrollado una serie de indicadores de anomalías y de riesgo (conocidos como «banderas rojas»), que sirven para activar la función de supervisión, pero que se pueden utilizar en términos más generales en las estrategias de prevención del riesgo de corrupción ${ }^{73}$.

En cuanto a la nueva regulación de los contratos públicos, revela algunas decisiones fundamentales en el contexto de un ajuste particularmente complejo e inestable (baste recordar que el último decreto correctivo, núm. 56 de 2017, consta de 131 artículos e innova profundamente, no solo «perfecciona» y corrige, el código de contratación del año anterior).

En general, las nuevas normas, que para la adquisición de suministros o servicios más estandarizados confirma la idea de recurrir a soluciones como las subastas electrónicas y se mueve a contracorriente respecto del enfoque que había caracterizado tradicionalmente, desde principios de los años 90 del siglo pasado, la relación entre la normativa de los contratos y la lucha contra la corrupción, es decir, la idea de una «fuga de la discrecionalidad» ${ }^{74}$, y, por lo tanto, se acepta un margen de decisión por parte de las administraciones a la hora de elegir al contratista, renunciando a mecanismos automáticos (como la oferta de precio inferior) a favor de espacios de valoración (como la oferta económicamente más ventajosa) ${ }^{75}$. Esto se explicita en especial en el art. 95, relativo a los «criterios de adjudicación del contrato», que apartado 2 establece que, como norma, «los órganos contratantes, de conformidad con los principios de transparencia, no discriminación e igualdad de trato, adjudicarán los contratos [... ] sobre la base del criterio de la oferta económicamente más ventajosa identificada en función de la mejor relación calidad-precio» teniendo en cuenta también el «ciclo de vida» del bien en cuestión.

Todo esto en un escenario en el que se apuesta mayormente por una mejor cualificación de los mismos órganos públicos contratantes, estableciendo que solo bajo ciertas condiciones es posible que una entidad realice de forma autónoma la función de órgano contratante, y que en otros casos deberá recurrir a órganos contratantes y "centrales de compras» adecuadamente cualificada ${ }^{76}$. El artículo 38 del código de contratación, en particular, regula la calificación de los órganos contratantes y las centrales de compras: una lista de órganos cualificados está en manos de la ANAC, y se elabora sobre la base de los requisitos técnicos y de organización inspirados en criterios de eficiencia, profesionalidad y calidad regidos por un decreto especial del Presidente del Consejo de Ministros (aún no aprobado): vale la pena mencionar el hecho de que, con fines de cualificación, la ley define los requisitos básicos y los requisitos preferibles, entre los que se incluye la «evaluación positiva de la ANAC en relación con la aplicación de medidas preventivas contra el riesgo de corrupción y la promoción de la legalidad».

Se presta asimismo mucha atención a la fiabilidad y la cualificación de las empresas, a partir de normas sólidas de exclusión, vinculadas a las facultades de supervisión y control no solo de documentos por parte de la ANAC, que están reguladas de forma muy detallada en el art. 80 del código de contratación: la intención es claramente la de excluir de las relaciones contractuales con las administraciones públicas a los sujetos «de riesgo» en sus variadas formas (porque, por ejemplo, están vinculados a asuntos de corrupción, lavado de dinero, declaraciones falsas, fraude, infiltración de la mafia, etc.).

Un número inferior de órganos contratantes, una mayor profesionalidad, la mejora de la capacidad de supervisión de estos por parte de la Autoridad, que también detenta mayores poderes para resolver proble-

72 En términos generales, cfr. A. ZULIANI, "Informazione per contrastare la corruzione", en Studi parlamentari e di politica costituzionale, 2013, págs. 75 y ss.

73 Sobre la cuestión de los indicadores de corrupción, y en particular sobre los previstos en este ámbito, cfr. Autorità Nazionale Anticorruzione e Presidenza del Consiglio dei Ministri - Dipartimento per le politiche di coesione, Analisi istruttoria per l'individuazione di indicatori di rischio corruzione e di prevenzione e contrasto nelle amministrazioni pubbliche coinvolte nella politica di coesione, 2017; Autorità anticorruzione, Corruzione sommersa e corruzione emersa in Italia: modalità di misurazione e prime evidenze empiriche, 2013 (ambos en www.anticorruzione.it).

74 A. VANNUCCI, "Il lato oscuro della discrezionalità. Appalti, rendite e corruzione", en G. D. COMPORTI (ed.), Le gare pubbliche: il futuro di un modello, Nápoles: ESI (2011), 265-296; G. FIDONE, "La corruzione e la discrezionalità amministrativa: il caso dei contratti pubblici", en Giornale di Diritto Amministrativo, 2015, págs. 325 y ss.

75 Sobre las características de este modelo, cfr. L. GILI, "La nuova offerta economicamente più vantaggiosa e la discrezionalità amministrativa a più fasi", en Urbanistica e appalti, 2017, fasc. 1, págs. 24 y ss.

76 Cfr. L. FIORENTINO, "Le centrali di committenza e la qualificazione delle stazioni appaltanti. Commento a d.lg. 18 aprile 2016, núm. 50", en Giornale di diritto amministrativo, 2016, fasc. 4, págs. 443-451; véase en especial M. MACCHIA, "La qualificazione delle amministrazioni appaltanti", en Giornale di diritto amministrativo, 2017, fasc. 1, págs. 50-59. 
mas críticos durante las licitaciones (es esta una cuestión controvertida, que se centra en un nuevo tipo de «recomendaciones vinculantes $»^{77}$ de la ANAC, en relación a la cual también se asiste a una cierta oscilación de las decisiones legislativas). En cualquier caso, este es el modelo alrededor del cual muchas de las disposiciones contenidas en el nuevo código de contratación, que responde además no solo a las exigencias nacionales de prevención de la corrupción, sino también a las europeas, enunciadas en las directivas, de mayor apertura a la competencia y a la mejora de la calidad de las obras, servicios y suministros.

En la nueva regulación de los contratos públicos se afirman mecanismos importantes para la transparencia de la toma de decisiones (a través de las obligaciones de publicación de las «reuniones y conversaciones con las partes interesadas», es decir, los grupos de presión) y de participación (con una solución inspirada en el modelo del «debat public» francés) $)^{78}$ : no se trata de un mecanismo que pueda ser leído exclusivamente desde un punto de vista de fortalecimiento de la imparcialidad, que demuestra, sin embargo, que los contratos son un «laboratorio» en el que se desarrollan soluciones innovadoras para la acción administrativa. Estas provisiones están contenidas en un artículo muy interesante, dedicado a la «transparencia en la participación de las partes interesadas y el debate público», art. 22 del código de contratación.

El campo de los contratos públicos también se caracteriza por un sistema mejorado de transparencia, que está estrechamente relacionado con el modelo de «transparencia total» ${ }^{79}$ : de conformidad con el art. 29, en efecto, «todos los actos de las administraciones y entidades adjudicadoras relacionados con el programa de trabajo, obras, servicios y suministros, así como los procedimientos de adjudicación de contratos públicos de servicios, suministros, obras y obras públicas, de concursos públicos de diseño, de concursos de ideas y de concesiones, [...], con la composición del comité de selección y con los currículos de sus miembros, [...], deberán ser publicados y actualizados en el perfil del organismo comprador, en la sección de "Administración Transparente" con la aplicación las disposiciones del decreto legislativo núm. 33 de 14 marzo de 2013».

\section{OBSERVACIONES FINALES}

El sistema de lucha contra la corrupción muestra, a la luz de esta rápida reseña, una serie de elementos y tendencias significativas: por un lado, es clara y coherente en su conjunto la evolución reciente de la legislación que va en la dirección de un fortalecimiento de las normas para garantizar la prevención de la corrupción, centradas en el papel de la Autoridad Nacional de Lucha Contra la Corrupción.

Por otro lado, no faltan elementos que merecen ser señalados y que contribuyen a construir un escenario más problemático.

Hemos señalado la atención limitada a la vertiente «política» del sistema de normas destinado a prevenir la corrupción: es una carencia cada vez más evidente y menos sostenible, que debe colmarse so pena de hacer poco eficaces en su conjunto, y poco creíbles, los numerosos mecanismos anticorrupción.

El funcionamiento de las diversas medidas de prevención sigue siendo demasiado débil y, por lo tanto, empiezan a advertirse los límites del sistema para contener los fenómenos de negligencia que siguen siendo comunes y emergen tanto a raíz de escándalos como de investigaciones judiciales o de los mismos datos sobre la percepción de la corrupción. El reto de la lucha contra la corrupción, en cuanto a la prevención, es un reto a largo plazo que requiere perseverancia y tiene como objetivo determinar los cambios organizativos y culturales que produzcan efectos a lo largo del tiempo: no obstante, existe el riesgo de crear desafección, como resultado de las altas expectativas generadas simplemente por la gran atención y visibilidad de la Autoridad Nacional y de las políticas contra la corrupción.

Esta desafección, fruto de una «traición» de las expectativas, está presente en particular en relación con otro de los puntos focales de las recientes reformas: la transparencia administrativa, especialmente en su manifestación más reciente de «freedom of information». Estos límites de aplicación corren el riesgo de ser utilizados, a veces incluso instrumentalmente, por un sistema político y administrativo que a menudo es hostil a las nuevas restricciones y a la exposición «a la luz del sol», con el fin de justificar un replanteamiento

77 Sobre ello, véase esp. M. LIPARI, 'La tutela giurisdizionale e 'precontenziosa' nel nuovo Codice dei contratti pubblici. Commento a d.Ig. 18 aprile 2016, núm. 50", en Federalismi.it, 2016, fasc. 10, págs. 1-43.

78 Sobre este punto, véase sintéticamente A. AVERARDI, "L'incerto ingresso del dibattito pubblico in Italia. Commento a d.Ig. 18 aprile 2016, núm. 50", en Giornale di diritto amministrativo, 2016, fasc. 4, págs. 505 y ss.

79 Cfr. en este sentido también las disposiciones incluidas en los arts. 37 y 38 del Decreto Legislativo núm. 33 del 2013; sobre el tema en general, cfr. esp. M. DE NES, "Contratti e opere pubbliche", en B. PONTI (ed.), Nuova trasparenza amministrativa e libertà di accesso alle informazioni, cit., págs. 406 y ss. 
general de diversos mecanismos de lucha contra la corrupción (empezando por los de transparencia total) y de los poderes mismos de la Autoridad Nacional de Lucha Contra la Corrupción.

En este contexto, especialmente una cierta ambigüedad presente en la política, y en las políticas legislativas, es motivo de preocupación: la cuestión de los poderes de la Autoridad en materia de contratos «misteriosamente» reducidos en el último minuto en la corrección del Código de Contratación, el intento (por el momento en espera) para eliminar la figura de los secretarios municipales que conforman el punto de referencia fundamental de la organización (como responsables de la prevención) de la «red» de lucha contra la corrupción, el excesivo papel otorgado al Garante de la Protección de Datos Personales en el sistema del nuevo derecho de acceso generalizado que se traduce en un debilitamiento de este mecanismo de transparencia, constituyen varias «señales de alerta» del riesgo de debilitar el sistema de lucha contra la corrupción.

A pesar de estas advertencias, y de estos límites, es evidente la importancia y la ambición de las reglas y políticas de lucha contra la corrupción llevada a cabo en Italia en los últimos cinco años: un diseño orgánico, de amplio espectro, que es probablemente la reforma más importante de la Administración que ha afectado al gobierno italiano en los últimos años y que nos entrega un «modelo» (aunque todavía por perfeccionar) de prevención de la corrupción que, no por casualidad, como se mencionó al principio, se utiliza como referencia en otros países europeos. 